\title{
COVID-19 Lockdown in Portugal: Challenges, Strategies and Effects on Mental Health
}

\author{
Diana Aguiar Vieira ${ }^{1}$ (D) $\cdot$ Viviana Meirinhos ${ }^{1}$ (1)
}

Accepted: 25 January 2021 / Published online: 2 March 2021

(C) Associação Brasileira de Psicologia 2021

\begin{abstract}
Identified in China at the end of 2019, the COVID-19 infection has increased exponentially worldwide. Together with the threat of physical illness, this pandemic brought negative impacts on mental health. Additionally, the pandemic also interfered with other life domains: closings of schools and companies, restricted access to public places, changes in work and home routines and increased uncertainty due to the economic repercussions. This study examines people's experiences and mental health in the 6th consecutive lockdown week in Portugal and compares with the preconfinement population's mental health. Specifically, we explore the difficulties experienced by the general population while in lockdown, their strategies to cope with it, and its impact on mental health. One thousand five hundred and two participants undergoing the 6th lockdown week answered a web-based cross-sectional survey. Demographic information, living conditions, confinement-related difficulties or challenges, strategies to cope with lockdown and mental health dimensions were assessed. Some difficult confined related experiences and sociodemographic variables were associated with poor mental health. When compared to our findings, the general population' mental health was better before the pandemic. Lockdown challenges experienced by participants and their strategies to cope with confinement predicted 10 to $42 \%$ of the variance in mental health dimensions. This study identified several mental health-protective and risk factors related to long-term compulsory confinement. Individual strategies to prevent mental health problems are discussed. Additionally, our findings may inform national health agencies and governments on measures to enhance mental health among the quarantined general population.
\end{abstract}

Keywords COVID-19. Confinement · Mental health - Lockdown · Pandemic $\cdot$ Quarantine

Diana Aguiar Vieira

dianaaguiarvieira@gmail.com

1 Porto Accounting and Business School, ISCAP, CEOS.PP, Polytechnic of Porto, Rua Jaime Lopes Amorim, s/n 4465-004 S, Mamede de Infesta, Portugal 


\section{Introduction}

First detected in China, in December 2019, the virus named "severe acute respiratory syndrome coronavirus 2" (SARS-CoV-2) rapidly spread around the world. On 11 March 2020, COVID-19 disease was declared a pandemic by the World Health Organization. Worldwide governments have responded to COVID-19 outbreak with several measures, such as travel restrictions, lockdown and physical distancing. These measures aim to restrict the spread of COVID-19 and prevent surpassing the capacity of current health systems response. In Portugal, the lockdown was imposed by the government on 18 March 2020. During the following 6 weeks, the general population was forbidden to use the public space, and compulsory confinement was legally imposed, except for shopping necessities and going to work when remote work was not possible.

While several people have been or will be infected with COVID-19, much more people have been or will experience fear, anxiety, stress and other negative consequences caused by pandemic (Grover et al. 2020; Marques et al. 2020). The unexpected pandemic crisis and the uncertainty about the future also threaten psychological wellbeing (Moura et al. 2020). Nevertheless, the great majority of research on this new coronavirus has been focused on medical issues. Although research for COVID-19 prevention and cure is fundamental, empirical studies on psychological and social impacts should be further developed (Chakraborty 2020; Huang and Zhao 2020; Marques et al. 2020; Passos et al. 2020).

A review of quarantine's psychological impact during previous major infectious disease outbreaks (i.e., Ebola, SARS) has identified adverse psychological effects such as depression, anxiety, post-traumatic stress symptoms and anger (Brooks et al. 2020; Lai et al. 2020). In the same line, several studies about COVID-19 pandemic have also found negative impacts on mental health (Banna et al. 2020; Canet-Juric et al. 2020; Chakraborty 2020; Huang and Zhao 2020; Pieh et al. 2020; Wang et al. 2020). Nevertheless, the call to increase research on general population mental health persists (Afonso and Figueira 2020; Arden and Chilcot 2020; Banna et al. 2020; Grover et al. 2020; Ornell et al. 2020).

Specifically, in Portugal, some studies on COVID-19 pandemic and mental health have been conducted. Some are literature reviews (Dos Santos et al. 2020; Figueiredo et al. 2020), others focus on specific populations such as secondary school students (Alves et al. 2020) or youth minorities (Gato et al. 2020). Furthermore, Branquinho et al. (2020) explores COVID-19 impact on adolescents lives, and Mendes-Santos et al. (2020) discuss digital mental health strategies. As far as our knowledge, among Portugal's general population, only two cross-sectional studies on the psychological impact during COVID-19 lockdown were conducted, both in the 1st week of the nation-wide official mandatory confinement (Moreira et al. 2020; Paulino et al. 2020). Additionally, a pos-confinement cross-sectional study on general population resident in Portugal or Brazil was conducted, after 3 weeks of the lockdown (Passos et al. 2020).

The official mandatory confinement in Portugal lasted 45 consecutive days, from 18 March 2020 to 2 May 2020. The present study examines people's experiences and mental health in the 6th consecutive lockdown week in Portugal. Specifically, we explore the difficulties and challenges experienced by the general population while in lockdown, their strategies to cope with it, and its impact on mental health. 


\section{Method}

\section{Participants}

One thousand and nineteen participants $(n=1619)$ answered the online survey. After excluding incomplete or invalid surveys, the final sample included 1562 participants. Seventy-three per cent of the participants are female, $23 \%$ male and $4 \%$ did not report it. Thirty-four per cent are 18-24 years old, 33\% are 25-45 years old, $28 \%$ are older than 45 years and $6 \%$ did not report their age group. The majority of the participants concluded a higher education degree (60\%), 33\% have secondary education or less and $7 \%$ did not report their educational level. Finally, the main activity for $58 \%$ of the participants is working, 34\% studying, 5\% are unemployed and 3\% did not report it.

\section{Confinement and Living Conditions}

The majority of participants $(65 \%)$ leave home only to go to the supermarket or pharmacy, while $20 \%$ are confined at home and never go out. Other participants are not confined because of work (14\%), and the remaining $1 \%$ go out every day due to other activities such as volunteering. Therefore, $85 \%$ of the total sample have been confined for the previous 5 weeks. Approximately one-third of participants (34\%) live with three other people in the same household, $28 \%$ with two people, $18 \%$ with one person, $11 \%$ with four people, $5 \%$ alone and $4 \%$ with five people or more. Due to the pandemic, $47 \%$ report income decrease and $67 \%$ increased the support given to children or elderly. Among the participants that work or study at home, $75 \%$ have a private home space to do it and $75 \%$ report having a computer. Finally, the house of $84 \%$ of participants has an outdoor space such as a balcony or garden.

\section{Procedures and Ethical Considerations}

The questionnaire was prepared on the Limesurvey Online Platform. Invitations to participate in the study was sent via the researchers' social networks and further disseminated to the general population through the snowball technique. Data were collected between April 23 and 28, 2020, during the 6th consecutive and mandatory confinement week, in Portugal. The average time to complete the survey was $11 \mathrm{~min}$.

For this study, all the procedures were guided by the ethical research standards of the Order of Portuguese Psychologists (CDOPP, DR 2 ${ }^{a}$ Série/ 2011, 2016). Accordingly, subjects were ensured that participation was anonymous and voluntary. Subjects were informed about the study' goals and the freedom to interrupt their participation at any time. Digital informed consent with mandatory acceptance to proceed was also provided. Additionally, this study was approved by the Bussiness and Accounting School at Polytechnic of Porto (ref. 20200423).

\section{Measures}

The online questionnaire was anonymous, and participation was voluntary. The introduction explained the study goals and confidentiality of individual results was guaranteed. The first question asked participants to provide their informed consent, and further 
questions were made available upon explicit participants' consent. The questionnaire was structured into three main parts: (1) confinement-related experiences (changes, challenges, difficulties and strategies), (2) mental health and (3) living conditions and demographics.

\section{Confinement-Related Experiences}

A national-wide lockdown for several weeks due to a pandemic was a completely new situation that has caused substantial changes to people's lives. Consequently, at the time of this study, knowledge about how people reacted to this unprecedented situation was scarce. Due to this unusual situation, a previous exploratory study aimed to facilitate the elaboration of relevant questions that could resonate with people's experiences was done. Therefore, three online focus groups, with 25 subjects, were conducted. Sixtyeight per cent participants were female and the age range 18-46 years old. The focus groups included students, workers and unemployed subjects. This qualitative study focused on exploring the difficulties felt and strategies used to deal with the lockdown. Content analysis of the focus groups' answers and quarantine related challenges and strategies studies found in the literature at that time were performed (Brooks et al. 2020; Marques et al. 2020; Ornell et al. 2020). These procedures allowed elaborating a set of closed questions to evaluate weight changes, sleep and eating patterns, confinement challenges and difficulties and strategies to cope with confinement.

\section{Weight, Sleep and Eating Changes}

Participants were asked about lockdown related changes in their weight, sleep and eating habits. For each question, participants selected one of the following options: "the same as before lockdown", "less", or "more".

\section{Confinement Challenges and Difficulties}

Participants were asked to report any changes in the frequency of 11 situations or experiences possibly associated with the confinement condition, such us, "It is difficult to concentrate" or "I miss being with work or school colleagues". Participants responded by choosing one of the following options: (a) "More times", (b) "Fewer times", (c) "Equal" and (d) "Not applicable".

\section{Strategies to Cope with Confinement}

Fifteen questions explored the strategies used by participants to cope with confinementrelated difficulties, such as "Chat with friends/relatives that are not in my home" and "Create a wish list to post-confinement". Participants responded "yes", "no", or "not applicable".

\section{Mental Health}

Mental health subscales of the SF-36v2 (Ware Jr. and Sherbourne 1992; adapted for the Portuguese population by Ferreira \& Ferreira and Santana 2003) were used in the 
present study, namely, vitality (i.e., energy and fatigue, 4 items), emotional role functioning (i.e., limitations in usual activities because of emotional problems, 3 items) and general mental health (i.e., psychologic distress and well-being, 5 items). Given the social restrictions during the lockdown, the present study did not include the social role functioning subscale. Each subscale score that varies from 0 to 100 and higher scores indicate more favourable self-reported mental health. Several reasons supported the decision to use SF-36v2 to measure mental health. First, we are experiencing a worldwide pandemic, and SF-36v2 facilitates comparisons across countries since it has been translated into more than 150 languages and validated in different cultures (AboAbat et al. 2020). Second, the SF-36v2 has been worldwide used to assess mental health and psychological symptoms in the general population, being our target population individuals living in the community (AboAbat et al. 2020; ten Klooster et al. 2013; Pfoh et al. 2016; Roser et al. 2019). Finally, SF-36v2 Portuguese norms are available which allows comparisons with the scores obtained in this study. In Portugal, reliability scores (Cronbach $\alpha$ ) of the SF-36v2 ranged from .60 to .87 (Ferreira 2000; Ferreira et al. 2012; Ferreira \& Ferreira and Santana 2003; Severo et al. 2006). In the present study, reliability estimates of the subscales were .76 for vitality (95\% CI, 0.74 to 0.78 ), .60 for emotional role functioning ( $95 \% \mathrm{CI}, 0.57$ to 0.64 ) and .85 for general mental health ( $95 \%$ CI, 0.84 to 0.86$)$. Given the low-reliability value for the subscale of emotional role functioning, one should be cautious about interpreting the sample results. Further comments and possible explanations for this finding will be provided in the Discussion section.

\section{Sociodemographics and Living Conditions}

Participants were asked to indicate their gender, age (18-25, 26-45, 46 or more), main activity (worker, student, unemployed) and educational level (higher education, secondary education or less). To measure participants' confinement level, we asked them to choose one of the following options: (1) "I am not confined at home because I have to go to work", (2) "I am not confined at home because I have activities that imply leaving home (i.e., volunteering)", (3) "I am confined at home, but sometimes I go out (i.e., shopping, pharmacy, walking)" and (4) "I am confined at home and never go out". Additionally, we included the next five questions related to their confinement situation: (a) "Due to the pandemic, have you increased the support given to children or the elderly?" (b) "Due to the pandemic, did your income decrease?" (c) "Does everyone in your household have an individual place to study or work?" (d) "In your household, does everyone who needs it have a computer?" (e) "Does your house have an outdoor space (i.e., balcony, garden)?". Participants responded "yes", "no" or "not applicable".

\section{Data Analysis}

Next, descriptive statistical for mental health dimensions in the total sample, by sociodemographic variables and confinement conditions, were calculated. Correlational analyses were performed for demographics and confinement conditions with health dimensions, except for the main activity variable for which we used analysis of variance. Post hoc comparisons were calculated using the Bonferroni test. Percentages for challenges, difficulties, and strategies while in confinement were reported for the 
total sample. Dummy variables were created for age, confined related challenges, and strategies to be used in multiple regressions to test association among the variables of interest. The response time approach was used to filter low motivated respondents (Huang et al. 2012; Meade and Craig 2012). Following the recommendation proposed by Wise and Kong (2005), the respondents that took less than 3 min to answer the questionnaire were excluded from the analyses. Multiple regressions results were analysed against a Bonferroni-adjusted alpha level of .016 (.05/3) to control for possible detrimental effects. All analyses were performed using IBM SPSS Statistics 24.0 for Windows.

\section{Results}

The total sample's mental health dimensions, by demographics and confinement conditions, are presented in Table 1. In the total sample, vitality dimension evidenced the lower score $(\mathrm{MVT}=49.03$, SDVT $=19.65)$, while the mental health dimension the highest $(\mathrm{MMH}=59.48, \mathrm{SDMH}=20.52)$. Next, we compared the means and standard deviation scores obtained in the total sample with the normative Portuguese values reported by Ferreira et al. (2012). This sample and the general population means and standard deviations were, respectively, for emotional function $55.08( \pm 20.17)$ vs $79.83( \pm 24.70)$, vitality $41.51( \pm 19.03)$ vs $63.00( \pm 23.06)$ and mental health $59.48( \pm 20.52)$ vs $72.97( \pm 23.27)$. As previously mentioned, the mean score for all SF-36v2 dimensions is 50.00 . Accordingly, it seems that in the present study, although emotional function and mental health dimensions showed mean scores above 50.00, these values were much lower when compared to the general population. Moreover, the sample's vitality values were below 50.00 and considerably much lower than the population's mean, indicating weaker energy levels and more substantial fatigue among participants.

Next, intercorrelations among participants' demographics, confinement conditions, and mental health dimensions were calculated (Table 2). Higher levels of emotional function were associated with older and more educated participants, lower confinement levels, absence of income decrease, fewer people at home and having access to an individual home workplace, as well as to a personal computer. Male, older and more educated participants, lower confinement levels, absence of income decrease, fewer people at home, access to an individual home workplace and a personal computer were associated with higher vitality levels. The same was true for more positive mental health, except for the number of people at home that showed no relation with this dimension. As expected, the relationships among the three health dimensions were all positive and statistically significant.

Next, analysis of variance between main activity and mental health dimensions were performed. Results indicated differences among the groups in emotional function $(F(2$, $1504)=58.11 ; p<.001)$, vitality $(F(2,1504)=23.83 ; p<.001)$ and mental health $(F(2$, $1504)=50.32 ; p<.001)$. Results from the Bonferroni post hoc tests showed that students reported more negative perceptions of vitality when compared to workers and unemployed participants $\left(M_{\text {Students }}=40.81<M_{\text {Workers }}=47.82, p<.001 ; M_{\text {Unemployed }}=\right.$ $46.55, p<.001)$. Workers indicated higher levels of emotional function $\left(M_{\text {Workers }}=\right.$ 
Table 1 Mental health dimensions descriptives in total sample, by sociodemographic variables and confinement conditions

\begin{tabular}{|c|c|c|c|c|c|c|c|}
\hline & & \multicolumn{2}{|c|}{ Emotional function } & \multicolumn{2}{|c|}{ Vitality } & \multicolumn{2}{|c|}{ Mental health } \\
\hline & & $M$ & $S D$ & $M$ & $S D$ & $M$ & SD \\
\hline \multicolumn{2}{|l|}{ Total sample } & 55.08 & 20.17 & 45.51 & 19.03 & 59.48 & 20.52 \\
\hline \multirow[t]{2}{*}{ Gender } & Male & 55.63 & 21.20 & 49.89 & 19.79 & 64.60 & 21.25 \\
\hline & Female & 55.08 & 19.80 & 44.11 & 18.57 & 58.05 & 20.03 \\
\hline \multirow[t]{3}{*}{ Age } & $<25$ & 49.11 & 20.16 & 40.79 & 17.53 & 53.04 & 20.43 \\
\hline & $25-45$ & 55.98 & 19.06 & 45.19 & 19.90 & 60.04 & 20.49 \\
\hline & $\geq 46$ & 61.93 & 19.06 & 51.52 & 17.96 & 66.58 & 18.13 \\
\hline \multirow[t]{2}{*}{ Education } & No HE & 51.03 & 20.34 & 42.54 & 19.04 & 54.50 & 21.20 \\
\hline & $\mathrm{HE}$ & 57.49 & 19.63 & 47.10 & 18.84 & 62.21 & 19.66 \\
\hline \multirow[t]{3}{*}{ Main Activity } & Worker & 59.45 & 19.01 & 47.82 & 18.78 & 63.37 & 19.29 \\
\hline & Student & 48.20 & 20.18 & 40.81 & 17.98 & 52.71 & 20.57 \\
\hline & Unemp. & 50.00 & 20.98 & 46.55 & 21.97 & 54.61 & 21.64 \\
\hline \multirow[t]{4}{*}{ Confin. level } & 1 & 58.52 & 18.80 & 45.51 & 18.88 & 60.25 & 19.13 \\
\hline & 2 & 53.47 & 22.60 & 50.00 & 14.35 & 64.58 & 17.12 \\
\hline & 3 & 54.97 & 20.25 & 46.67 & 19.04 & 60.51 & 20.19 \\
\hline & 4 & 53.06 & 20.40 & 41.58 & 19.00 & 55.41 & 22.03 \\
\hline \multirow[t]{2}{*}{ Own space to work } & No & 50.99 & 21.23 & 39.34 & 18.87 & 54.78 & 20.71 \\
\hline & Yes & 56.36 & 19.86 & 47.33 & 18.44 & 61.03 & 20.22 \\
\hline \multirow[t]{2}{*}{ Own computer } & No & 51.12 & 19.99 & 42.27 & 17.21 & 55.94 & 19.58 \\
\hline & Yes & 56.52 & 20.17 & 46.40 & 19.47 & 60.59 & 20.81 \\
\hline \multirow[t]{2}{*}{ Outdoor space } & No & 52.33 & 21.46 & 42.08 & 20.38 & 55.96 & 21.66 \\
\hline & Yes & 55.60 & 19.83 & 46.10 & 18.66 & 60.12 & 20.22 \\
\hline \multirow[t]{2}{*}{ Support increase } & No & 56.48 & 20.72 & 46.71 & 18.67 & 61.51 & 20.28 \\
\hline & Yes & 54.81 & 19.59 & 45.18 & 18.62 & 59.46 & 20.14 \\
\hline \multirow[t]{2}{*}{ Income decrease } & No & 59.64 & 19.39 & 47.49 & 18.86 & 62.10 & 20.02 \\
\hline & Yes & 52.35 & 20.21 & 44.19 & 19.19 & 57.78 & 20.90 \\
\hline
\end{tabular}

$M$ mean, $S D$ standard deviation, $H E$ higher education, Confin. level confinement level: 1 = "I am not confined at home because I have to go to work", 2 = "I am not confined at home because I have activities that imply leaving home (i.e., volunteering)", 3 = "I am confined at home, but sometimes I go out (i.e., shopping, pharmacy, walking)", 4 = "I am confined at home and never go out"; Support increase $=$ increase in the support given to children and elderly

$\left.59.45>M_{\text {Students }}=48.20, p<.001 ; M_{\text {Unemployed }}=50.00, p<.001\right)$ as well as in mental health $\left(M_{\text {Workers }}=63.37>M_{\text {Students }}=40.81, p<.001 ; M_{\text {Unemployed }}=54.61, p<.01\right)$, when compared to students and unemployed participants.

Approximately half of the total participants reported lockdown related changes in weight (12\% decrease; $34 \%$ increase), sleeping hours (28\% decrease; $30 \%$ increase) and food intake (10\% decrease; $42 \%$ increase). Among these, the most common change was an increase in food intake.

The challenges and difficulties experienced while in confinement are presented in Table 3. Not meeting family members/friends and work/study colleagues were the most 


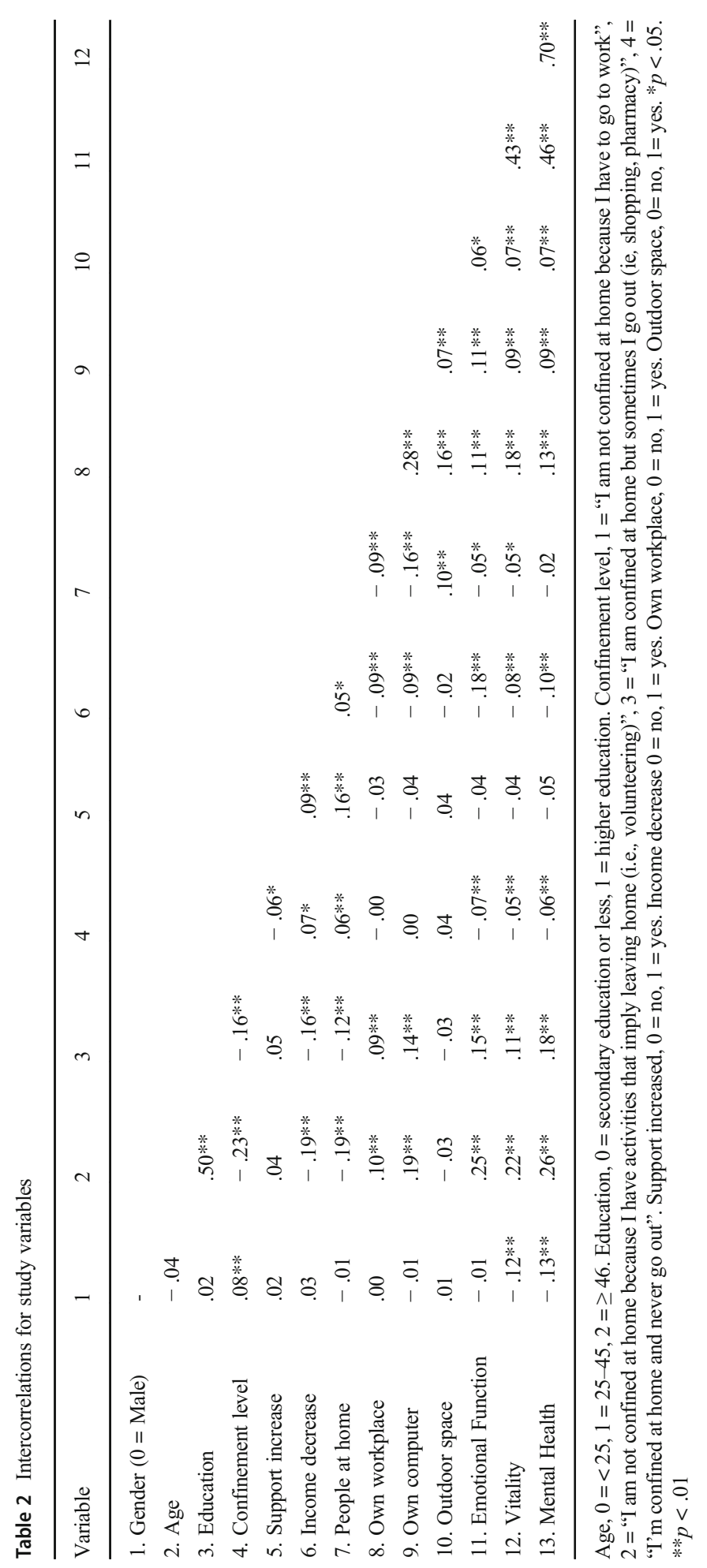


frequently reported difficulties ( $92 \%$ and $80 \%$, respectively). Feeling overwhelmed by being at the computer and feeling impatient were also difficulties felt very often by participants in this study (63\% and 61\%, respectively). Additionally, more than half of participants reported difficulty to concentrate (58\%), no motivation to perform daily activities (54\%), difficulty in maintaining a sleep routine (53\%) and difficulty in managing time $(51 \%)$.

Strategies to deal with confinement are presented in Table 4. Chatting with friends/ relatives who were not living in the same house was the most common strategy to deal with confinement. This finding is not surprising if we consider that not being able to meet with family and friends was reported as the most frequent difficulty experienced while in confinement. Other strategies frequently used by participants were watching entertainment programs (81\%), using social media (79\%), listening to music $(75 \%)$, doing physical exercise (62\%) and cooking new recipes $(58 \%)$.

Next, a series of hierarchical regressions were performed to test if the confined related challenges and difficulties could predict mental health dimensions. Because previous analyses have shown that age was the most robust demographic variable associated with mental health dimensions (see Table 2), we created two dummy variables for age, using the younger group as the reference group $(<24$ years old). These age variables were introduced in the first step of the analysis. After converting challenges and difficulties variables into dummy variables $(0=$ same frequency experienced before confinement, 1 = increased frequency due to confinement), these were introduced in the second step. Table 5 presents the results from hierarchical regression analyses to test if the confined related challenges and difficulties could predict mental health.

Twenty-nine per cent of the emotional function's variance was explained by the ability to concentrate, manage time, maintain a sleep routine and feel motivated to daily activities, together with being 46 years old or more (compared to $<25$ age group). Vitality was predicted by the ability to concentrate, work-life balance, maintain a sleep routine, feel motivated to daily activities and not getting upset with the others, together

Table 3 Confinement-related challenges and difficulties

More times than before

$\begin{array}{lc}\text { I miss being with my family and friends } & 92 \% \\ \text { I miss being with work and school colleagues } & 80 \% \\ \text { I feel overwhelmed by being at the computer } & 63 \% \\ \text { I feel impatient } & 61 \% \\ \text { I find it difficult to concentrate } & 58 \% \\ \text { I am not motivated to perform daily activities } & 54 \% \\ \text { It is difficult to maintain a sleep routine } & 53 \% \\ \text { I find it difficult to manage time } & 51 \% \\ \text { I get easily annoyed } & 49 \% \\ \text { I find work-life balance difficult } & 47 \% \\ \text { I get upset with the others } & 29 \%\end{array}$


Table 4 Strategies to deal with confinement

\begin{tabular}{lc}
\hline & Yes \\
\hline Chat with friends/relatives who are not living with me & $89 \%$ \\
Watch entertainment programs (i.e., series, movies) & $81 \%$ \\
Use social media & $79 \%$ \\
Listen to music to relax & $75 \%$ \\
Cook new recipes & $65 \%$ \\
Do physical exercise & $62 \%$ \\
Do playful activities (i.e., play, draw) & $55 \%$ \\
Have deeper conversations with those who are living with me & $50 \%$ \\
Avoid watching the news about the pandemic & $50 \%$ \\
Plan activities for each day & $50 \%$ \\
Get dressed as I did before lockdown & $38 \%$ \\
Take online courses & $28 \%$ \\
Practice meditation or relaxation & $28 \%$ \\
Create a wish list to post-lockdown & $20 \%$ \\
Call the COVID-19 psychological support line & $1 \%$ \\
\hline
\end{tabular}

with being 46 years old or more (compared to $<25$ age group), in $32 \%$ of its variance. Finally, the mental health model showed the highest predictive power (42\%) by the ability to concentrate, feel motivated to daily activities, maintain a sleep routine, not getting upset with the others and, again, being 46 years old or more (compared to $<25$ age group). In sum, age, challenges and difficulties were able to predict mental health dimensions, explaining 29 to $42 \%$ of their variance.

Subsequently, we run a series of multiple regression analyses to explore if participants' strategies to cope with confinement could predict mental health dimensions. As in the previous regression analyses, age dummy variables were introduced in the first step, followed by dummy variables created for strategies $(0=$ did not use this strategy to cope with confinement, $1=$ used this strategy to cope with confinement). These results are presented in Table 6.

Better emotional function, vitality and mental health were predicted by age (older than 24 years old). Avoiding watching the news about the pandemic and using social media contributed to lower levels in all mental health dimensions. Adding the strategy of planning each day's activities, the whole model accounted for $10 \%$ of the variance in emotional function. Higher levels of vitality and mental health dimensions were also positively associated with dressing in the same way as before confinement, and the practice of physical exercise. Additionally, higher levels in the mental health dimension were likewise predicted by chatting more deeply with those living in the household and engaging in playful activities (i.e., games), while the practice of meditation/relaxation predicted lower levels. The models explainned $12 \%$ and $14 \%$ of the variance in vitality and mental health dimensions, respectively. In conclusion, it seems that age and strategies to cope with confinement were able to predict mental health dimensions, explaining 10 to $14 \%$ of their variance. 


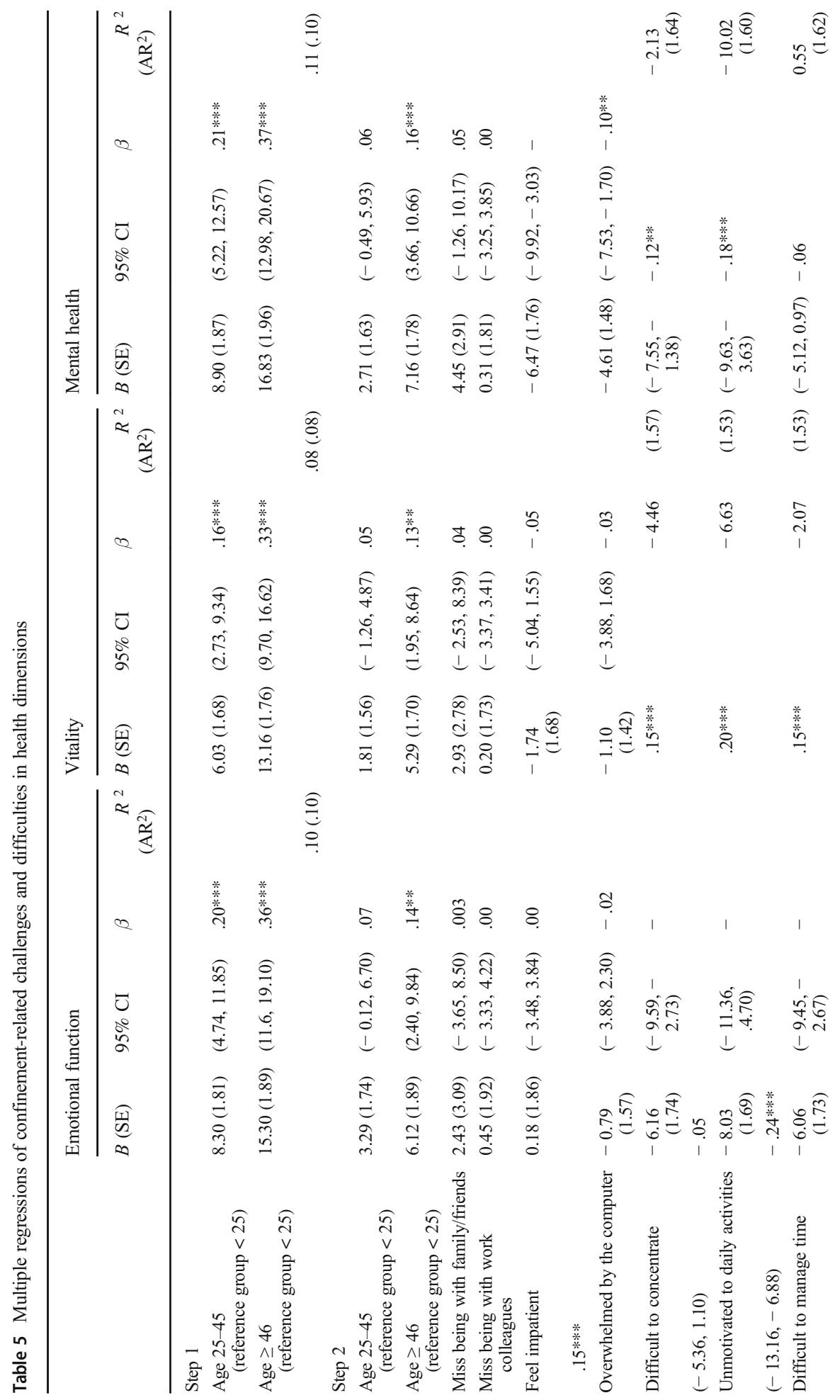




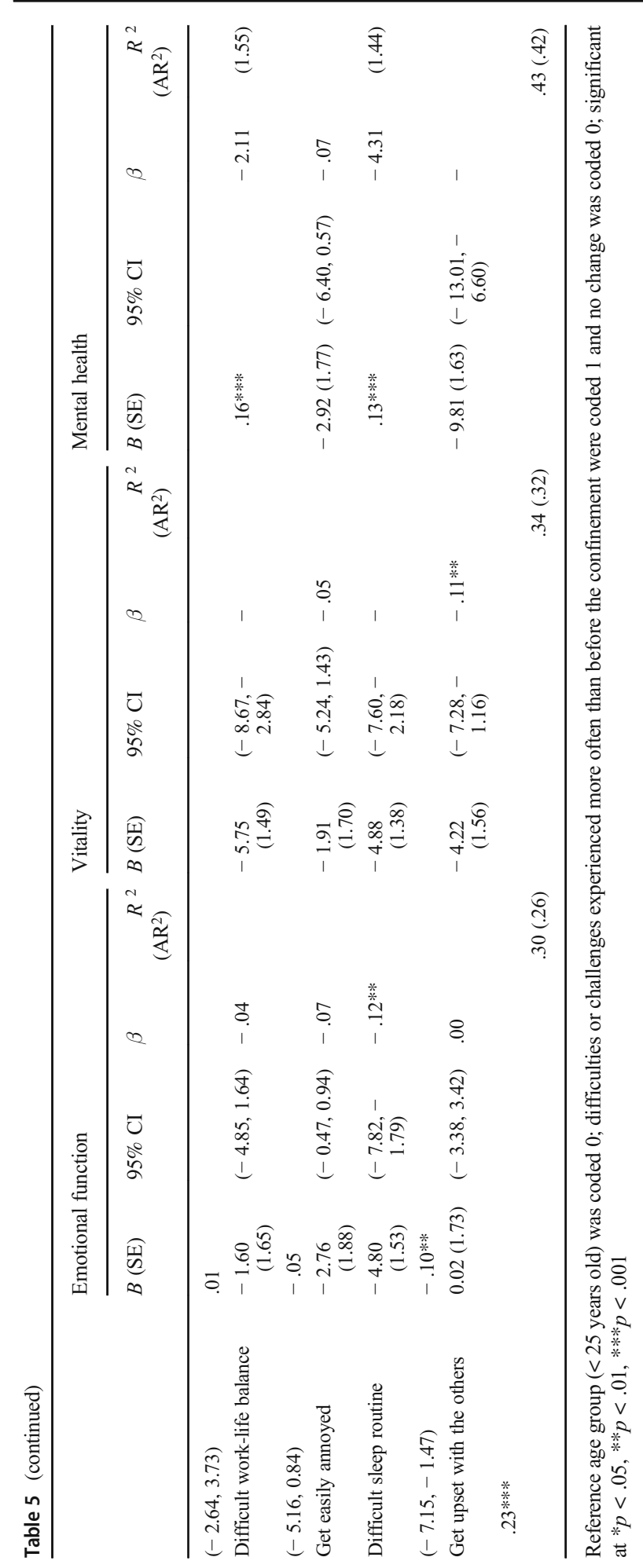




\section{Discussion}

This research examined the difficulties and challenges experienced by the general population in the 6th week in compulsory confinement, their strategies to cope with it, and its potential impact on mental health. First, we explored the influence of sociodemographic characteristics on mental health. Our findings suggest that gender and education were associated with mental health dimensions. Being female and having a lower educational level (against higher education credentials) were associated with poorer mental health. Similar differences have been found in previous studies in Portugal (Amorim 2009; Ferreira et al. 2012; Ferreira \& Ferreira and Santana 2003; Moreira et al. 2020; Paulino et al. 2020) as well as in other countries (Brooks et al. 2020; Roser et al. 2019; Wang et al. 2020). We found better mental health in workers than in students or unemployed participants. In line with these findings, other studies found similar results (Amorim 2009; Brooks et al. 2020; Ferreira et al. 2012; Ferreira \& Ferreira and Santana 2003; Roser et al. 2019). Because education and employment are proxies for socioeconomic status, our findings suggest that the socioeconomically disadvantaged people are more prone to experience lower mental health. Consequently, this may constitute a specific group that calls for increased support during pandemic times.

Age was the sociodemographic variable that showed the highest association with mental health dimensions. All mental health dimensions considered in the present study, namely emotional function, vitality and general mental health, were positively associated with age. Younger people also reported higher mental health problems than older people in other studies conducted either before (Roser et al. 2019) or during COVID-19 pandemic (Brooks et al. 2020; Huang and Zhao 2020; Paulino et al. 2020; Pieh et al. 2020). The lower mental health results revealed by younger participants deserves particular concern. If such mental health fragility is associated with age itself, it could mean that a more extensive restriction may be felt by the confined younger than for older people. However, one should consider that the younger participants were mainly higher education students who, due to the mandatory confinement, suddenly started taking online classes, lost social contact with colleagues and teachers, and felt a considerably increased demand for their self-regulation capabilities. Future research is needed to explore if the lower levels of mental health among confined younger people are strictly related to age or whether being a higher education student can help understand our findings.

Lockdown measures are essential to decrease the virus's spreading, but the findings in this research suggest that less restrictive confinement levels may be associated with better mental health. When the general population are in compulsory home confinement, national health authorities could explore the adequacy of allowing, or even advising people to safely leave home a few times a week. This measure could possibly benefit from preventing higher levels of mental health problems among the general population. Whether this measure is compatible with the disease control is up to epidemiologic professionals to determine.

\section{Challenges, Difficulties and Mental Health}

In line with other studies, our findings suggest that income decrease was associated with poorer mental health (Branquinho et al. 2020; Bosma et al. 2012; Brooks et al. 2020). 


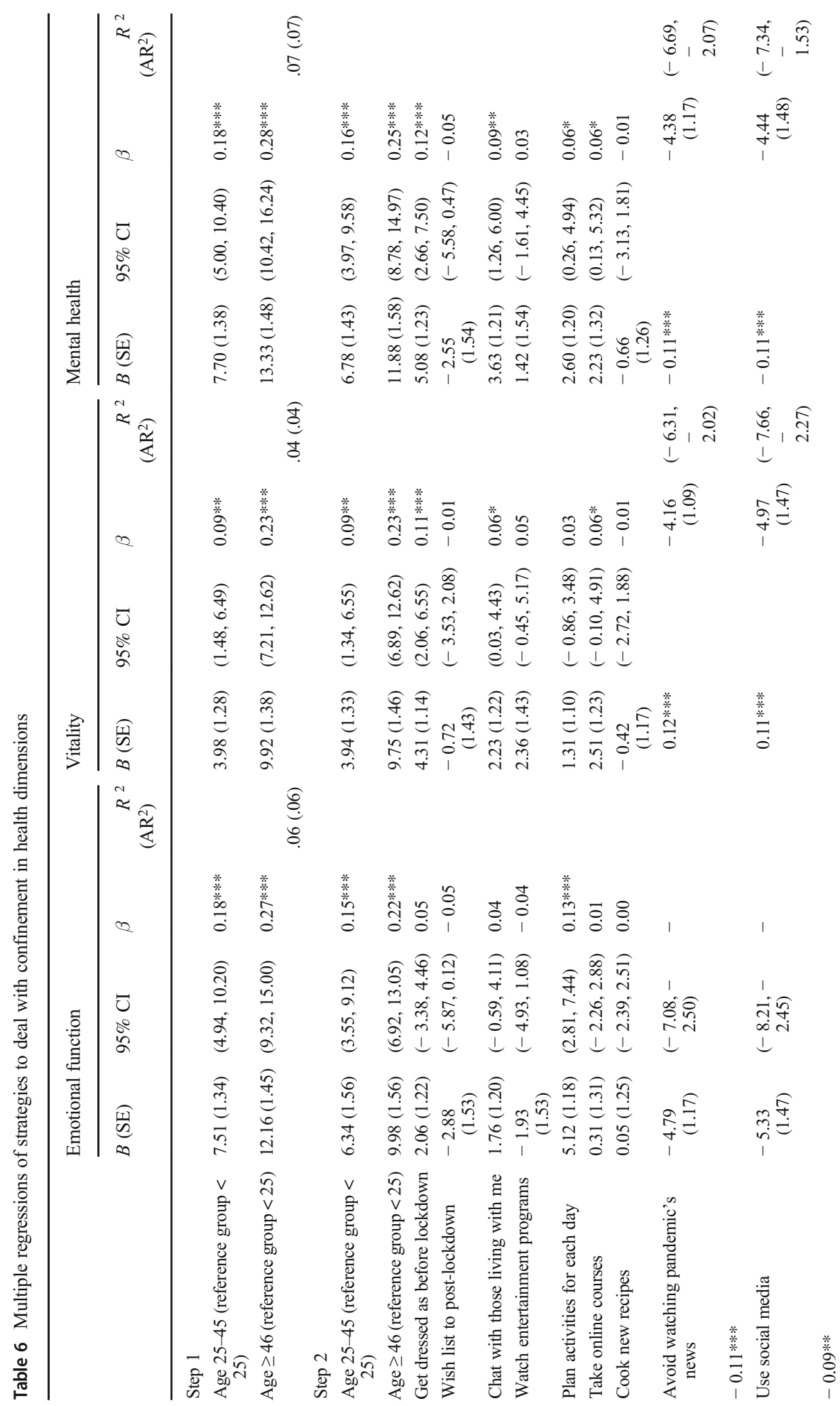




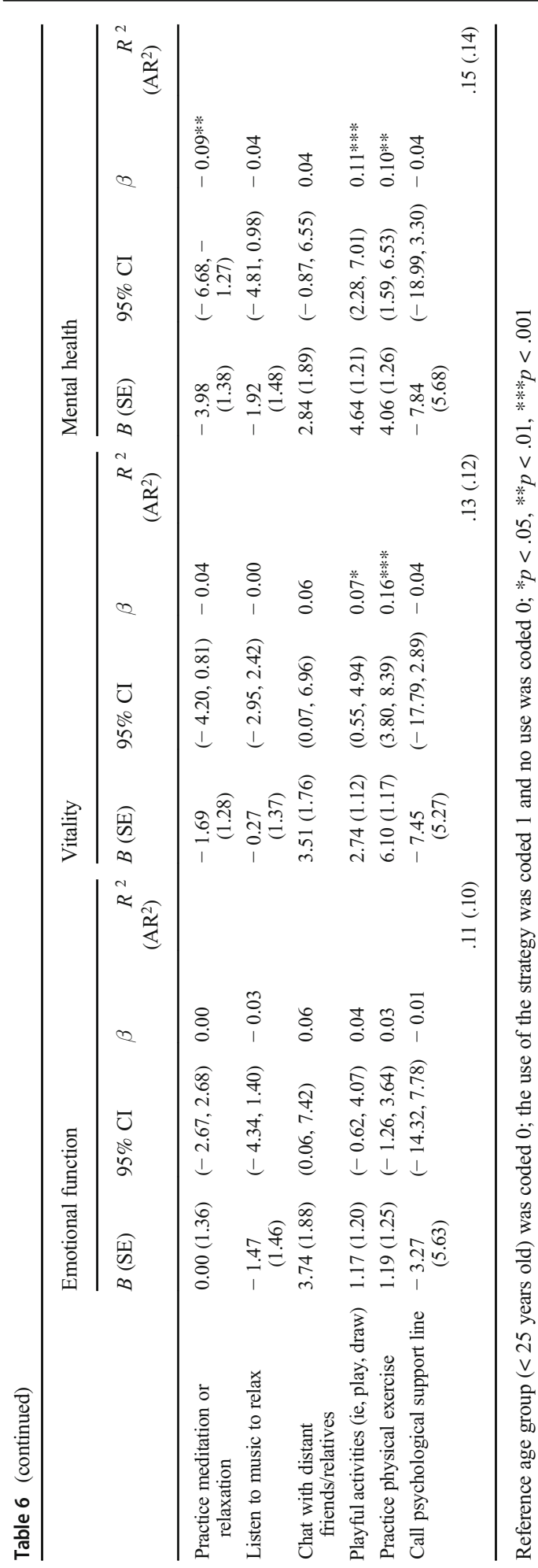


Several political measures to minimise economic problems among works, organisations and unemployed persons have already be applied in Portugal. Our study reinforces the importance of these measures, shedding light on their benefits on mental health.

Our study suggests that fewer people living in the same home, outdoor space at home, having access to an individual workplace at home, and a personal computer, were associated with better mental health. Similar findings may be found in other studies that have explored the associations between living conditions and psychological well-being during quarantine (Bezerra et al. 2020; Moreira et al. 2020). The high density of inhabitants per household and the absence of a unique homeplace to work or study are challenging living conditions whose change is difficult. Nonetheless, some measures can be identified for those who need to work or study remotely and have no personal computer access. In these cases, companies and universities could provide a personal computer for every worker or student that needs to work or study from home. Eventually, if this measure is not possible, those who do not have a personal computer could work in the company as long as the social distance is respected. On the part of higher education institutions, a similar measure could be implemented. Although we are aware that the suggested measures may not be easy to implement, it seemed important to reflect on actions supported by our findings, which could positively impact mental health.

Regular eating and sleeping may be especially important to mitigate the longterm effects of stress (Bezerra et al. 2020; Marques et al. 2020). However, approximately half of the total participants in this study reported lockdown related changes in weight, food intake and hours of sleep. Similar results were reported in other studies (Canet-Juric et al. 2020; Di Renzo et al. 2020). These findings require attention given that basic physiological needs such as nutrition and sleep are related to core health behaviours linked to a healthy lifestyle (Booker and Mullan 2013; Nudelman et al. 2019). Additionally, in the present study, difficulty in maintaining sleep routine was associated with poorer mental health which is in line with previous research focused on the importance of good-quality sleep to positive mental health conditions, either before (Kyle and Henry 2017) or during COVID-19 pandemic (Canet-Juric et al. 2020; Casagrande et al. 2020; Pinto et al. 2020). These findings may shed light on specific sleep-related procedures that may minimise the negative psychological impact caused by long-term home confinement. When a quarantine is required, national public health agencies could create programs to disseminate information on strategies to improve sleep quality, in the population.

The most frequent difficulties reported by the participants in this study were not meeting family members, friends and colleagues from office or university, feeling overwhelmed by being at the computer and feeling impatient. The most common strategies to deal with confinement were communicating regularly with friends and family via phone or video calls, watching entertainment programs, using social media and listening to music.

Our study also aimed at comparing mental health in our sample, which was experiencing the 6th lockdown week with the data from the general population, obtained before confinement. Our findings suggest that participants' mental health was lower than in the general population, especially in energy levels and fatigue. 
Another goal of the present study was to evaluate if there were associations of the reported difficulties and strategies with mental health. Because our study was crosssectional, no causal relation could be established. Several challenges and difficulties reported by participants seemed to be associated with lower mental health. Among them, difficulties in time management and work-life balance, lack of motivation to daily activities, and increased frequency of feeling impatient and upset with the others were identified. Consequently, to prevent or ameliorate mental health problems, national health agencies could provide large-scale psychoeducational programmes on time management, self-regulation, and conflict management aimed at the general population.

\section{Individual Strategies to Deal with Confinement and Mental Health}

This study identified several strategies that may contribute to better mental health. In general, dressing as before the lockdown, plan the activities for each day, playful activities, and physical exercise were associated with better mental health. These strategies are at the individual level and may be used during the lockdown. It is worth noting that, among the strategies explored in this study, the practice of physical exercise showed the strongest association with better mental health. Similarly, other studies reported a positive association between physical activity and better mental health, during prolonged COVID-19 lockdown periods (Bezerra et al. 2020; Matias et al. 2020; Pieh et al. 2020).

Several studies found that frequent exposure to pandemic news was associated with poorer mental health (Canet-Juric et al. 2020; Huang and Zhao 2020; Olagoke et al. 2020). In the same line, other studies recommend limiting news consumption about major infectious disease outbreaks (Marques et al. 2020; Ornell et al. 2020). Therefore, it was expected that avoiding to watch the news could have a positive association with mental health. Nevertheless, in this study, avoidance of watching the news was associated with poorer mental health. One possible explanation to this finding may be linked to the quality of the official COVID-19 information provided by the Portuguese TV news. In fact, quality information transmitted by public health authorities has been identified as beneficial in the case of pandemics (Brooks et al. 2020; Korajlija and Jokic-Begic 2020; Taha et al. 2014). However, future studies are needed to explore these issues further.

In the present study, using social media showed a negative association with mental health. However, Brooks et al. (2020) pointed out that social media may contribute to mental health by allowing quarantined people to contact their loved ones and reassure that they are well. In the present study, the way participants used social media was not explored. Future studies on social media use during quarantine could explore these aspects in more depth.

Future research may shed light on the intriguing result that associated the practice of relaxation or meditation with more fragile mental health. However, as these strategies are commonly used in therapeutic settings for reducing anxiety, it could be that the participants who reported using them may also have sought professional help. Consequently, this might be a proxy to mental health problems previous to the pandemic. Whether or not this is the case, future studies should explore these findings. 


\section{Limitations and Future Research}

One of the main limitations of this study is that the sample is biassed towards higherlevel education. Therefore, the sample is not representative of the population. Possibly, this circumstance may have contributed to the low-reliability score for the SF-36v2 subscale of emotional role functioning. Indeed, reliability scores may vary among particular homogeneous samples and specific contexts (Bernardi 1994; Hogan and Agnello 2004; Maroco and Garcia-Marques 2006). Together, these facts call for cautions about the generalisation of our findings. Consequently, when interpreting the results, these limitations have to be considered. Another consideration that should be taken into account relates to the cross-sectional nature of this study which does not allow causal conclusions.

The lack of information on participants' pre-confinement mental health is another limitation of the present study. Post-quarantine assessment is needed to exploring confinement long-term effects on mental health. Likewise, comparing two measurement points (in vs after lockdown) may further help understand mental health variations.

Finally, another limitation of the present study is the absence of information about the degree of exposure to COVID-19 disease. In other words, we do not know if the participants are health professionals neither if COVID-19 has infected them or someone close to them. Since these factors may influence mental health, this information should be taken into account in future studies.

\section{Final Considerations}

As far as our knowledge, this was the first study on confinement-related difficulties and challenges experienced by the general population, their strategies to cope with it and its impact on mental health, in the 6th consecutive lockdown week in Portugal. At the time of writing, the compulsory lockdown in Portugal was over. Nevertheless, the negative impact on mental health will probably last beyond the COVID-19 pandemic. It is expected that the postpandemic period will be a difficult one, not only in terms of mental health but also in social and economic terms (Afonso 2020; Asmundson and Taylor 2020; Brooks et al. 2020).

The "new normal life" has been calling for social distancing, using masks in public spaces and for many, working or studying remotely. The number of infected people worldwide continues to increase as well as the fear of being infected or of infecting others. Consequently, people still isolate themselves and avoid being with those they love, particularly with the older ones.

This study focused on the perceptions of people in mandatory quarantine during the lockdown in Portugal. Although our findings cannot be generalised, we hope to have delivered valuable information that may help prevent mental health problems in people under quarantine. By providing knowledge about the difficulties and challenges the general population is experiencing and their association with mental health, we hope to stimulate mental health prevention and psychoeducation measures to reduce mental health problems in these unprecedented times. 
Code Availability Not applicable.

Data Availability Data supportting the findings of this study are available from the corresponding author upon reasonable request.

\section{Declarations}

Conflict of Interest The authors declare no conflicts of interest.

\section{References}

AboAbat, A., Qannam, H., Bjorner, J. B., \& Al-Tannir, M. (2020). Psychometric validation of a Saudi Arabian version of the sf-36v2 health survey and norm data for Saudi Arabia. Journal of Patient-Reported Outcomes, 4(1), 67. https://doi.org/10.1186/s41687-020-00233-6.

Afonso, P. (2020). O impacto da pandemia COVID-19 na saúde mental [The impact of the COVID-19 pandemic on mental health]. Acta Médica. Portuguesa, 33, 356-357. https://doi.org/10.20344/amp.13877.

Afonso, P., \& Figueira, L. (2020). Pandemia COVID-19: quais são os riscos para a saúde mental? [Pandemic COVID-19: What are the risks for mental health?]. Revista Portuguesa de Psiquiatria e Saúde Mental, 6 , 2-3 https:/www.revistapsiquiatria.pt/index.php/sppsm/article/view/131/53.

Alves, R., Samorinha, C., \& Precioso, J. (2020). Conhecimentos, atitudes e comportamentos de estudantes Portugueses do ensino secundário relacionados com a prevenção da COVID-19 [Knowledge, attitudes and behaviours of Portuguese secondary school students related to the prevention of COVID-19]. PSICOLOGIA, 34(2), 75-88. https://doi.org/10.17575/psicologia.v34i2.1659.

Amorim, M. (2009). Para lá dos números...Aspectos psicossociais e qualidade de vida do indivíduo com diabetes mellitus tipo 2. [Beyond the numbers ... Psychosocial aspects and quality of life of individuals with diabetes mellitus type 2] [Doctoral Thesis, Instituto de Ciências Biomédicas Abel Salazar, Universidade do Porto]. https://repositorio-aberto.up.pt/handle/10216/7211.

Arden, M. A., \& Chilcot, J. (2020). Health psychology and the coronavirus (COVID-19) global pandemic: A call for research. British Journal of Health Psychology, 25(2), 231-232. https://doi.org/10.1111/bjhp.12414.

Asmundson, G. J. G., \& Taylor, S. (2020). Coronaphobia: Fear and the 2019-nCoV outbreak. Journal of Anxiety Disorders, 70, 102-196. https://doi.org/10.1016/j.janxdis.2020.102196.

Banna, M. H. A., Sayeed, A., Kundu, S., Christopher, E., Hasan, M. T., Begum, M. R., ... Khan, M. S. I. (2020). The impact of the COVID-19 pandemic on the mental health of the adult population in Bangladesh: a nationwide cross-sectional study. International Journal of Environmental Health Research, 1-12. doi:https://doi.org/10.1080/09603123.2020.1802409

Bernardi, R. A. (1994). Validating research results when Cronbach'S alpha is below .70: A methodological procedure. Educational and Psychological Measurement, 54(3), 766-775. https://doi.org/10.1177/ 0013164494054003023.

Bezerra, A. C. V., Silva, C. E. M., Soares, F. R. G., \& Silva, J. A. M. (2020). Fatores associados ao comportamento da população durante o isolamento social na pandemia de COVID-19 [Factors associated with population behavior during social isolation in the COVID-19 pandemic]. Ciência \& Saúde Coletiva, 25(1), 2411-2421. https://doi.org/10.1590/1413-81232020256.1.10792020.

Booker, L., \& Mullan, B. (2013). Using the temporal self-regulation theory to examine the influence of environmental cues on maintaining a healthy lifestyle. British Journal of Health Psychology, 18(4), 745762. https://doi.org/10.1111/bjhp.12015.

Bosma, H., Gerritsma, A., Klabbers, G., \& van den Akker, M. (2012). Perceived unfairness and socioeconomic inequalities in functional decline: The Dutch SMILE prospective cohort study. BMC Public Health, 12, 818 .

Branquinho, C., Kelly, C., Arevalo, L. C., Santos, A., \& de Matos, M. G. (2020). "Hey, we also have something to say": A qualitative study of Portuguese adolescents' and young people's experiences under COVID-19. Journal of Community Psychology, 48(8), 2740-2752. https://doi.org/10.1002/jcop.22453.

Brooks, S. K., Webster, R. K., Smith, L. E., Woodland, L., Wessely, S., Greenberg, N., \& Rubin, G. J. (2020). The psychological impact of quarantine and how to reduce it: Rapid review of the evidence. The Lancet, 395(10227), 912-920. https://doi.org/10.1016/S0140-6736(20)30460-8. 
Canet-Juric, L., Andrés, M. L., del Valle, M., López-Morales, H., Poó, F., Galli, J. I., Yerro, M., \& Urquijo, S. (2020). A longitudinal study on the emotional impact cause by the COVID-19 pandemic quarantine on general population. Frontiers in Psychology, 11. https://doi.org/10.3389/fpsyg.2020.565688.

Casagrande, M., Favieri, F., Tambelli, R., \& Forte, G. (2020). The enemy who sealed the world: Effects quarantine due to the COVID-19 on (sleep) quality, anxiety, and psychological distress in the Italian population. Sleep Medicine, 75, 12-20. https://doi.org/10.1016/j.sleep.2020.05.011.

Chakraborty, N. (2020). The COVID-19 pandemic and its impact on mental health. Progress in Neurology and Psychiatry, 24(2), 21-24. https://doi.org/10.1002/pnp.666.

Di Renzo, L., Gualtieri, P., Pivari, F., Soldati, L., Attina, A., Cinelli, G., et al. (2020). Eating habits and lifestyle changes during COVID-19 lockdown: an Italian survey. Journal of Translational Medicine, 18 , 229. https://doi.org/10.1186/s12967-020-02399-5.

Dos Santos, C. F., Picó-Pérez, M., \& Morgado, P. (2020). COVID-19 and mental health—what do we know so far? Frontiers in Psychiatry, 11. https://doi.org/10.3389/fpsyt.2020.565698.

Ferreira, P. (2000). Criação da Versão Portuguesa do MOS SF-36, Parte II - Testes de validação [Development of the Portuguese version of MOS SF-36, part II - validation tests]. Acta Médica Portuguesa, 13, 119-127 https://www.actamedicaportuguesa.com/revista/index.php/amp/article/view/1770.

Ferreira, P. L., \& Santana, P. (2003). Perceção do estado de saúde e de qualidade de vida da população activa: Contributo para a definição de normas portuguesas [Perception of the health status and quality of life of the active population: Contribution to the definition of Portuguese standards]. Revista Portuguesa de Saúde Pública, 21(2), 15-30 https://estudogeral.sib.uc.pt/handle/10316/13656.

Ferreira, P. L., Ferreira, L. N., \& Pereira, L. N. (2012). Medidas sumário física e mental de estado de saúde para a população portuguesa [Physical and mental summary measures of health status for the Portuguese population]. Revista Portuguesa de Saúde Pública, 30(2), 163-171. https://doi.org/10.1016/j.rpsp.2012.12.007.

Figueiredo, C., Cunha, M., Sousa, L., \& Santos, E. (2020). Impacto psicológico da pandemia da covid-19 na população geral [Psychological impact of the covid-19 pandemic on the general population: systematic review protocol with meta-analysis]. Millenium - Journal of Education, Technologies, and Health, 7e, 11-16. https://doi.org/10.29352/mill0207e.01.00360.

Gato, J., Leal, D., \& Seabra, D. (2020). Quando a casa não é um porto seguro: Efeitos da Pandemia COVID19 em Jovens de Minorias Sexuais e de Género em Portugal [When the home is not a safe haven: Effects of the pandemic COVID-19 on youths of sexual and gender minorities in Portugal]. PSICOLOGIA, 34(2), 89-100. https://doi.org/10.17575/psicologia.v34i2.1667.

Grover, S., Dua, D., Sahoo, S., Mehra, A., Nehra, R., \& Chakrabarti, S. (2020). Why all COVID-19 hospitals should have mental health professionals: The importance of mental health in a worldwide crisis! Asian Journal of Psychiatry, 51, 102-147. https://doi.org/10.1016/j.ajp.2020.102147.

Hogan, T. P., \& Agnello, J. (2004). An empirical study of reporting practices concerning measurement validity. Educational and Psychological Measurement, 64(5), 802-812. https://doi.org/10.1177/0013164404264120.

Huang, Y., \& Zhao, N. (2020). Generalised anxiety disorder, depressive symptoms and sleep quality during COVID-19 outbreak in China: A web-based cross-sectional survey. Psychiatry Research, 288, 112954. https://doi.org/10.1016/j.psychres.2020.112954.

Huang, J. L., Curran, P. G., Keeney, J., Poposki, E. M., \& DeShon, R. P. (2012). Detecting and deterring insufficient effort responding to surveys. Journal of Business and Psychology, 27(1), 99-114. https://doi. org/10.1007/s10869-011-9231-8.

Korajlija, A. L., \& Jokic-Begic, N. (2020). COVID-19: Concerns and behaviours in Croatia. British Journal of Health Psychology, 25, 1-7. https://doi.org/10.1111/bjhp.12425.

Kyle, S. D., \& Henry, A. L. (2017). Sleep is a modifiable determinant of health: Implications and opportunities for health psychology. British Journal of Health Psychology, 22(4), 661-670. https://doi.org/10.1111/bjhp.12251.

Lai, J., Ma, S., Wang, Y., Cai, Z., Hu, J., Wei, N., Wu, J., Du, H., Chen, T., Li, R., Tan, H., Kang, L., Yao, L., Huang, M., Wang, H., Wang, G., Liu, Z., \& Hu, S. (2020). Factors associated with mental health outcomes among health care workers exposed to coronavirus disease 2019. JAMA Network Open, 3(3), e203976-e203976. https://doi.org/10.1001/jamanetworkopen.2020.3976.

Maroco, J., \& Garcia-Marques, T. (2006). Qual a fiabilidade do alfa de Cronbach? Questões antigas e soluções modernas? [How reliable is Cronbach's alpha? Old issues and modern solutions]. Laboratório de Psicologia, 4(1), 65-90. https://doi.org/10.14417/lp.763.

Marques, L., Bartuska, A. D., Cohen, J. N., \& Youn, S. J. (2020). Three steps to flatten the mental health need curve amid the COVID-19 pandemic. Depression and Anxiety, 37(5), 405-406. https://doi.org/10.1002/da.23031.

Matias, T., Dominski, F. H., \& Marks, D. F. (2020). Human needs in COVID-19 isolation. Journal of Health Psychology, 25(7), 871-882. https://doi.org/10.1177/1359105320925149.

Meade, A. W., \& Craig, S. B. (2012). Identifying careless responses in survey data. Psychological Methods, 17(3), 437-455. https://doi.org/10.1037/a0028085. 
Mendes-Santos, C., Andersson, G., Weiderpass, E., \& Santana, R. (2020). Mitigating COVID-19 impact on the Portuguese population mental health: The opportunity that lies in digital mental health. Frontiers in Public Health, 8. https://doi.org/10.3389/fpubh.2020.553345.

Moreira, P. S., Ferreira, S., Couto, B., Machado-Sousa, M., Fernández, M., Raposo-Lima, C., Sousa, N., Picó-Pérez, M., \& Morgado, P. (2020). Protective elements of mental health status during the COVID-19 outbreak in the Portuguese population. MedRxiv, 2020(04), 28.20080671. https://doi.org/10.1101/2020.04.28.20080671.

Moura, G. G., Nascimento, C. R. R., \& Ferreira, J. M. (2020). COVID-19: Reflections on the crisis, transformation, and interactive processes under development. Trends in Psychology. https://doi.org/10. 1007/s43076-020-00061-z.

Nudelman, G., Kalish, Y., \& Shiloh, S. (2019). The centrality of health behaviours: A network analytic approach. British Journal of Health Psychology, 24, 215-236.

Olagoke, A. A., Olagoke, O. O., \& Hughes, A. M. (2020). Exposure to coronavirus news on mainstream media: The role of risk perceptions and depression. British Journal of Health Psychology, 25, 865-874. https://doi.org/10.1111/bjhp.12427.

Ornell, F., Schuch, J. B., Sordi, A. O., Kessler, F. H. P., Ornell, F., Schuch, J. B., Sordi, A. O., \& Kessler, F. H. P. (2020). "Pandemic fear" and COVID-19: Mental health burden and strategies. Brazilian Journal of Psychiatry, 42(3), 232-235. https://doi.org/10.1590/1516-4446-2020-0008.

Passos, L., Prazeres, F., Teixeira, A., \& Martins, C. (2020). Impact on mental health due to COVID-19 pandemic: cross-sectional study in Portugal and Brazil. International Journal of Environmental Research and Public Health, 17(18), 6794. https://doi.org/10.3390/ijerph17186794.

Paulino, M., Dumas-Diniz, R., Brissos, S., Brites, R., Alho, L., Simões, M. R., \& Silva, C. F. (2020). COVID19 in Portugal: exploring the immediate psychological impact on the general population. Psychology, Health \& Medicine, 1-12. https://doi.org/10.1080/13548506.2020.1808236.

Pieh, C., Budimir, S., \& Probst, T. (2020). The effect of age, gender, income, work, and physical activity on mental health during coronavirus disease (COVID-19) lockdown in Austria. Journal of Psychosomatic Research, 136, 110186. https://doi.org/10.1016/j.jpsychores.2020.110186.

Pfoh, E. R., Chan, K. S., Dinglas, V. D., Cuthbertson, B. H., Elliott, D., Porter, R., Bienvenu, O. J., Hopkins, R. O., \& Needham, D. M. (2016). The SF-36 offers a strong measure of mental health symptoms in survivors of acute respiratory failure. A tri-national analysis. Annals of the American Thoracic Society, 13(8), 1343-1350. https://doi.org/10.1513/AnnalsATS.201510-705OC.

Pinto, J., van Zeller, M., Amorim, P., Pimentel, A., Dantas, P., Eusébio, E., Neves, A., Pipa, J., Santa Clara, E., Santiago, T., Viana, P., \& Drummond, M. (2020). Sleep quality in times of Covid-19 pandemic. Sleep Medicine, 74, 81-85. https://doi.org/10.1016/j.sleep.2020.07.012.

Roser, K., Mader, L., Baenziger, J., Sommer, G., Kuehni, C. E., \& Michel, G. (2019). Health-related quality of life in Switzerland: Normative data for the SF-36v2 questionnaire. Quality of Life Research, 28(7), 19631977. https://doi.org/10.1007/s11136-019-02161-5.

Severo, M., Santos, A. C., Lopes, C., \& Barros, H. (2006). Fiabilidade e Validade dos Conceitos Teóricos das Dimensões de Saúde Física e Mental da Versão Portuguesa do Mos SF-36 [Reliability and validity of theoretical concepts of physical and mental health dimensions of the Portuguese version of Mos SF-36]. Acta Médica Portuguesa, 19, 281-288 https://www.actamedicaportuguesa.com/revista/index.php/amp/article/view/968.

Taha, S., Matheson, K., Cronin, T., \& Anisman, H. (2014). Intolerance of uncertainty, appraisals, coping, and anxiety: The case of the 2009 H 1 N 1 pandemic. British Journal of Health Psychology, 19, 592-605. https://doi.org/10.1111/bjhp.12058.

ten Klooster, P. M., Vonkeman, H. E., Taal, E., Siemons, L., Hendriks, L., de Jong, A. J. L., Dutmer, E. A. J., van Riel, P. L. C. M., \& van de Laar, M. A. F. J. (2013). Performance of the Dutch SF-36 version 2 as a measure of health-related quality of life in patients with rheumatoid arthritis. Health and Quality of Life Outcomes, 11(1), 77. https://doi.org/10.1186/1477-7525-11-77.

Wang, C., Pan, R., Wan, X., Tan, Y., Xu, L., Ho, C. S., \& Ho, R. C. (2020). Immediate psychological responses and associated factors during the initial stage of the 2019 coronavirus disease (COVID-19) epidemic among the general population in China. International Journal of Environmental Research and Public Health, 17(5), 1729. https://doi.org/10.3390/ijerph17051729.

Ware Jr., J., \& Sherbourne, C. D. (1992). The MOS 36-item short-form health survey (SF-36): I. Conceptual framework and item selection. Medical Care, 30(6), 473-483 https://journals.lww.com/lww-medicalcare/ Abstract/1992/06000/The_MOS_36_ltem_Short_Form_Health_Survey_SF_36_.2.aspx.

Wise, S. L., \& Kong, X. (2005). Response time effort: A new measure of examinee motivation in computerbased tests. Applied Measurement in Education, 18(2), 163-183. https://doi.org/10.1207/ s15324818ame1802 2. 